\title{
MAGNESIUM PERCHLORATE AS AN ALTERNATIVE WATER TRAP IN AMS GRAPHITE SAMPLE PREPARATION: A REPORT ON SAMPLE PREPARATION AT KCCAMS AT THE UNIVERSITY OF CALIFORNIA, IRVINE
}

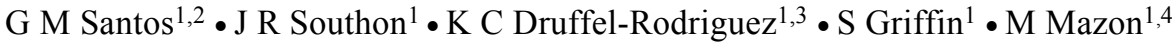

ABSTRACT. We present a brief discussion of sample preparation procedures at the Keck Carbon Cycle Accelerator Mass Spectrometer (KCCAMS), University of California, Irvine, and a systematic investigation of the use of $\mathrm{Mg}\left(\mathrm{ClO}_{4}\right)_{2}$ as an absorptive water trap, replacing the standard dry ice/ethanol cold finger in graphite sample preparation. We compare high-precision AMS measurement results from oxalic acid I and USGS coal samples using $\mathrm{Mg}\left(\mathrm{ClO}_{4}\right)_{2}$ under different conditions. The results obtained were also compared with those achieved using the conventional water removal technique. Final results demonstrate that the use of $\mathrm{Mg}\left(\mathrm{ClO}_{4}\right)_{2}$ as an alternative water trap seems very convenient and reliable, provided the $\mathrm{Mg}\left(\mathrm{ClO}_{4}\right)_{2}$ is replaced frequently.

\section{THE KCCAMS PREP LABORATORY}

A new sample processing laboratory was constructed and installed at the Keck Carbon Cycle Accelerator Mass Spectrometer (KCCAMS) facility in late 2002 to expand existing University of California, Irvine (UCI) radiocarbon sample handling capabilities. The KCCAMS prep laboratory has provided approximately 1500 unknown samples and quality control standards during the first 10 months of operation.

The prep laboratory is equipped for routine chemical sample cleaning and preparation of organic samples and carbonates. It also contains a sample-combustion system, 2 graphitization lines, and an accelerator target pressing station. The combustion line has 10 pump-out heads, while each graphitization line has $12 \mathrm{H}_{2} / \mathrm{Fe}$ reactors (Figure 1a, b), allowing us to graphitize 48 organic or carbonate samples per day. The vacuum lines are made of glass and stainless steel and are pumped by turbomolecular pumps backed by oil-free diaphragm pumps. Water is removed during graphitization either by using magnesium perchlorate- $\mathrm{Mg}\left(\mathrm{ClO}_{4}\right)_{2}$ - in the graphite-reactor, or by cold fingers attached to stainless steel thermoses converted to dry ice/alcohol dewars. The progress of the reaction is monitored using pressure transducers (Figure 1b). The design was based on sample graphitization lines from CAMS/Lawrence Livermore National Laboratory (LLNL).

\section{SAMPLE PREPARATION PROCEDURES}

Submitted samples from carbonaceous raw materials are chemically and/or physically pretreated, when necessary, to remove any unwanted material before conversion to carbon dioxide by combustion or acid hydrolysis. Organic samples are pretreated initially by removal of any visually obvious contamination, followed by a standard acid-alkaline-acid treatment. Carbonate samples are leached in dilute $\mathrm{HCl}$. Sample are then rinsed twice with MilliQ water and dried on a heating block at $80^{\circ} \mathrm{C}$.

Carbon dioxide is produced from pre-leached carbonates by acid hydrolysis using $85 \%$ phosphoric acid in disposable septum-sealed reactors (Vacutainer blood collection vials, $3 \mathrm{ml}$ ) (Figure 2a, b). Carbonates are weighed into the Vacutainers and evacuated using a 1.3-cm-long \#26 hypodermic Luer-tip needle adapted to an Ultra-torr fitting in the graphitization line (Figure 2b). Once the Vacu-

\footnotetext{
${ }^{1}$ Earth System Science, University of California, Irvine, B321 Croul Hall, Irvine, California 92697-3100, USA.

${ }^{2}$ Corresponding author. Email: gdossant@uci.edu.

${ }^{3}$ Department of Chemistry, Loyola Marymount University, Seaver Hall, Los Angeles, California, USA.

${ }^{4}$ Department of Biology, California State University, Fullerton, California, USA.
} 


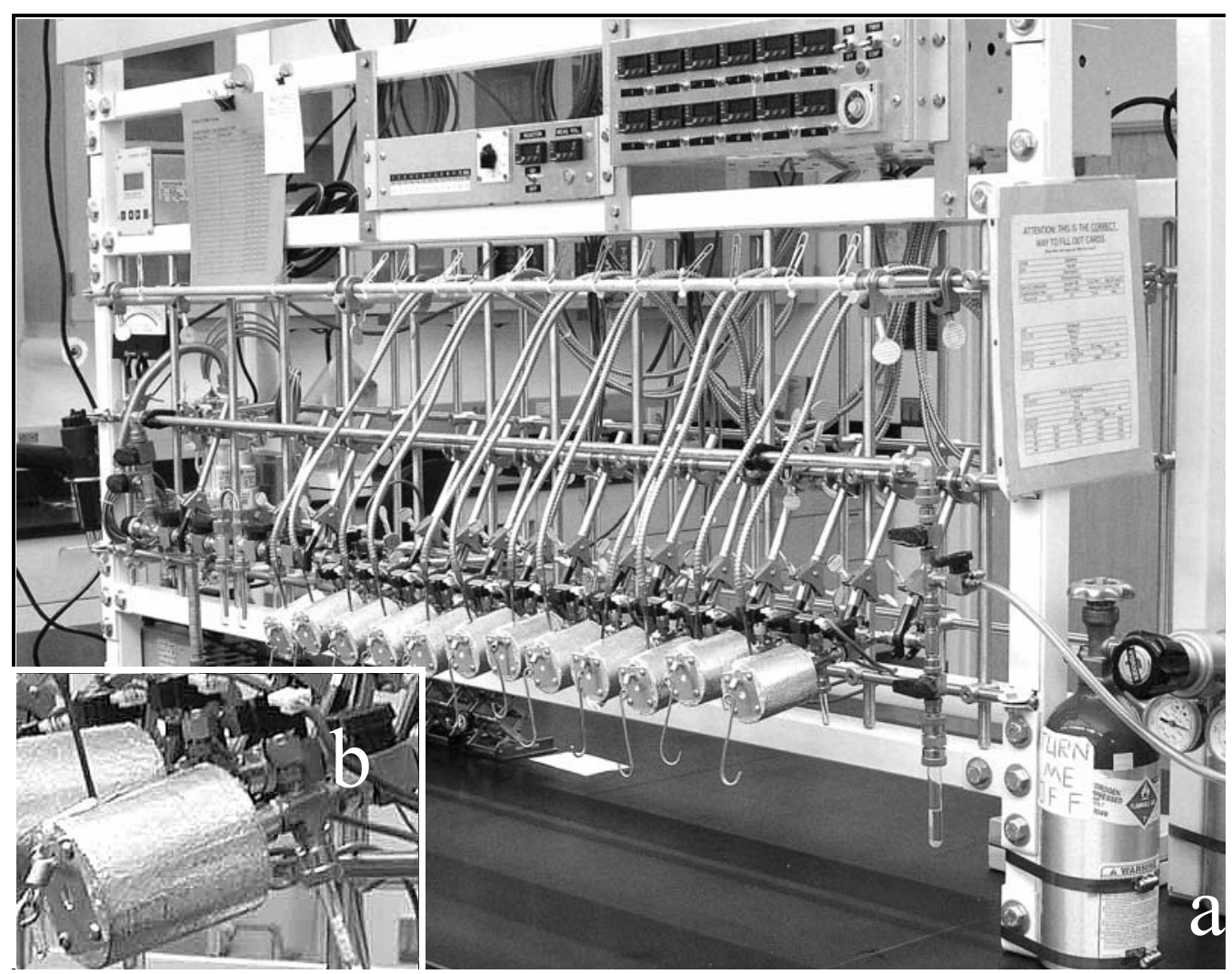

Figure 1 a) Graphitization line for target preparation showing $\mathrm{H}_{2} / \mathrm{Fe}$ reduction reactors. Each 12-head graphitization line can produce 24 samples per day. The design is based on graphitization lines from the CAMS/LLNL laboratory. b) Reduction reactor detail showing $\mathrm{Mg}\left(\mathrm{ClO}_{4}\right)_{2}$ in the graphite-reactor.

tainers are evacuated, we detach the vial from the line and use a gas-tight Luer-lock syringe with a \#26 needle to introduce $1 \mathrm{cc}$ of $85 \%$ phosphoric acid (Figure 2a). The Vacutainer reactors are then placed on heating-blocks at $80^{\circ} \mathrm{C}$ for at least $20 \mathrm{~min}$. When the reaction ceases, they are returned to the graphitization line to extract the $\mathrm{CO}_{2}$ via the needle fitting. To ensure complete evacuation of the needle fitting prior to $\mathrm{CO}_{2}$ extraction, the needle is initially inserted halfway through the Vacutainer septum. The $\mathrm{CO}_{2}$ is cryogenically purified and reduced to graphite in pyrex $6 \times 50 \mathrm{~mm}$ culture tubes (Loyd et al. 1991), using hydrogen at $650^{\circ} \mathrm{C}$ for $3-4 \mathrm{hr}$ over pre-baked iron. Since the Vacutainer vials are disposable, cleaning and waste handling after sample preparation are minimized.

The carbon dioxide production of organic samples is performed by combustion at $900{ }^{\circ} \mathrm{C}$ in evacuated sealed quartz tubes in the presence of $\mathrm{CuO}$ and silver wire. After $\mathrm{CO}_{2}$ extraction and purification, $\mathrm{CO}_{2}$ is then reduced to graphite as described above.

Samples prepared on these lines have demonstrated $56 \mathrm{ka}$ and $54 \mathrm{ka}$ BP backgrounds for organic and carbonate materials, respectively, for samples containing $1 \mathrm{mg}$ of carbon (Southon et al., these proceedings). 


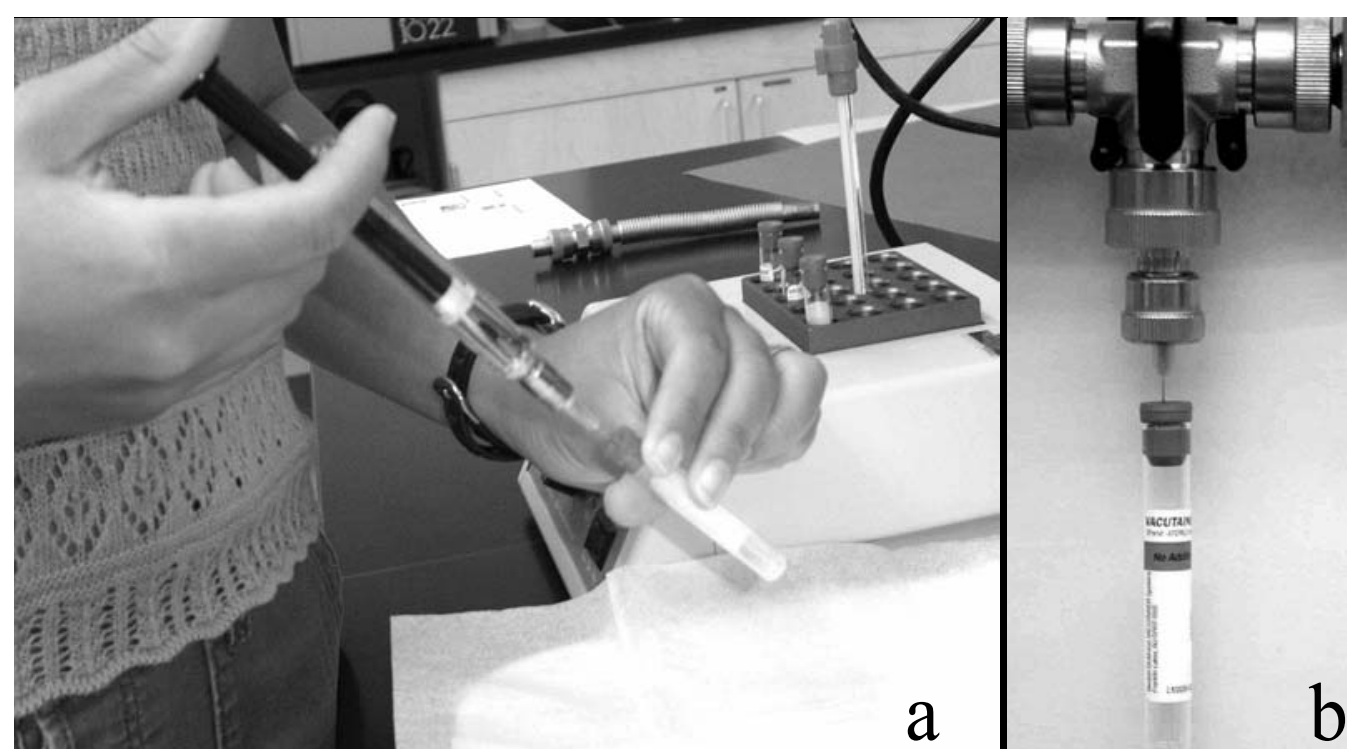

Figure 2 Acid hydrolysis procedure for carbonate sample. (a) $1 \mathrm{cc}$ of $85 \%$ phosphoric acid being introduced into septumsealed reactors (Vacutainer vials). (b) Detail of Vacutainer attached to the graphitization line for evacuation. The base of a \#26 hypodermic needle is placed in an Ultra-torr fitting, between the Ultra-torr ferrule and the sealing o-ring.

\section{Use of Magnesium Perchlorate for Water Removal}

Magnesium perchlorate is a well-known hygroscopic substance that has been used worldwide in the desiccant columns of stable isotope mass spectrometers. For more than $10 \mathrm{yr}, \mathrm{Mg}\left(\mathrm{ClO}_{4}\right)_{2}$ has been used to trap water during hydrogen reduction for graphite sample preparation at the UCI labs (S Zheng, personal communication).

At that time, UCI graphite was being measured at the LLNL AMS facility, where precision was initially $0.6 \%$ (J Southon, personal communication). These first investigations of the use of the substance in the graphitization process demonstrated its suitability, and 3 main advantages were immediately apparent: a) it is a very easy material to handle, allowing the user to replace it easily in the graphite-reactor in a very short period of time; b) it removes the need to prepare dry ice/ethanol slushes for each individual graphite-reactor, which can be time consuming; and c) the $\mathrm{Mg}\left(\mathrm{ClO}_{4}\right)_{2}$ water-trap could be re-used many times (also providing more time saving) without compromising the final measurement precision, as was demonstrated by multiple measurements of standards ( $\mathrm{S}$ Trumbore, personal communication).

In 2002, UCI installed a compact AMS from the National Electrostatics Corporation (0.5MV $1.5 \mathrm{SDH}-1 \mathrm{AMS}$ system). AMS ${ }^{14} \mathrm{C}$ precision for measurements performed with this system is currently between 0.2 to $0.5 \%$, based on multiple measurements of oxalic acid-I (OX-I) for hydrogen reduced graphite using Fe or Co catalyst (Southon et al., these proceedings). Accuracy is being evaluated on measurement results of secondary standards, such as oxalic acid-II (OX-II) and ANU sucrose (ANU), where 4\% fluctuations can be observed.

Since ${ }^{14} \mathrm{C}$ measurement precision has varied and some of the variation may be due to isotopic fractionation during sample preparation, we decided to perform a systematic comparison of the use of cryogenic mixtures or absorption in $\mathrm{Mg}\left(\mathrm{ClO}_{4}\right)_{2}$ to remove water during the graphitization reaction. Unusual variations on background samples beyond $50 \mathrm{ka}$ also indicated a possible memory 
or contamination effect from the $\mathrm{Mg}\left(\mathrm{ClO}_{4}\right)_{2}$ (or water trapped in the perchlorate), which was typically being used for 10 to 15 graphitizations before replacement based on absorptive saturation of the substance.

\section{EXPERIMENT AND RESULTS}

In the first experiment, 4 independently combusted samples of USGS coal and 4 of oxalic acid I (OX-I) were generated, each with enough material to be split into 3 aliquots. The $\mathrm{CO}_{2}$ from each sample was purified and shared equally among 3 graphite-reactors operated under different conditions, generating the graphite-aliquots $981.1,981.2$, and 981.3 , for example. We compare the effects of saturated and unsaturated $\mathrm{Mg}\left(\mathrm{ClO}_{4}\right)_{2}$, and pumping on the graphite-reactors for different periods of time before use (6 times previously used perchlorate and 90 min pumping time-group 1;6 times previously used and 10 min pumping time-group 2 ; and wet perchlorate and 10 min pumping timegroup 3). A set of 12 OX-I samples and 12 coal samples were graphitized and measured by AMS.

In the second experiment, 3 independently combusted samples of USGS coal and 3 samples of OXI were generated, each with enough material to be split into 4 aliquots. The $\mathrm{CO}_{2}$ from each sample was purified and shared equally among 4 graphite-reactors. In this case, we compared the use of cryogenic mixtures (group A), fresh perchlorate (group B), and previously used dry (group C) and wet (group D) perchlorate, for water removal. A set of 12 OX-I samples and 12 coal samples were graphitized and measured by AMS.

In the third experiment, we repeat the same conditions applied to the second experiment (Table 1) for the OX-I samples, but using $\mathrm{Mg}\left(\mathrm{ClO}_{4}\right)_{2}$ that had been previously used 8 times. We also pumped the graphite-reactor (i.e. on the perchlorate) for a longer period of time (60 min). A set of 12 OX-I samples were graphitized and measured by AMS.

Table 1 Summary of the water removal conditions in the graphitization reactor for the 3 experiments.

First
group 1- $\mathrm{Mg}\left(\mathrm{ClO}_{4}\right)_{2}$ used 6 times previously; reactor was pumped for $90 \mathrm{~min}$
group 2- $\mathrm{Mg}\left(\mathrm{ClO}_{4}\right)_{2}$ used 6 times previously; reactor was pumped for $10 \mathrm{~min}$
group 3- $\mathrm{Mg}\left(\mathrm{ClO}_{4}\right)_{2}$ used 6 times previously and exposed to MQ water vapor; reactor was
pumped for $10 \mathrm{~min}$
Second
group A-Dry ice and ethyl alcohol cold finger; reactor was pumped for $20 \mathrm{~min}$
group B-Fresh $\mathrm{Mg}\left(\mathrm{ClO}_{4}\right)_{2} ;$ reactor was pumped for 20 min
group $\mathrm{C}-\mathrm{Mg}\left(\mathrm{ClO}_{4}\right)_{2}$ used 2 times previously; reactor was pumped for 20 min
group D- $\mathrm{Mg}\left(\mathrm{ClO}_{4}\right)_{2}$ used 2 times previously and exposed to MQ water vapor; reactor
was pumped for 20 min
Third
group I-Dry ice and ethyl alcohol cold finger; reactor was pumped for 60 min
group II-Fresh $\mathrm{Mg}_{2}\left(\mathrm{ClO}_{4}\right)_{2} ;$ reactor was pumped for 60 min
group III- $\left.\mathrm{Mg}(\mathrm{ClO})_{4}\right)_{2}$ used 8 times previously; reactor was pumped for 60 min
group IV- $\mathrm{Mg}\left(\mathrm{ClO}_{4}\right)_{2}$ used 8 times previously and exposed to MQ water vapor; reactor
was pumped for 60 min

Water removal and pumping conditions from the graphite-reactors from the 3 experiments were designated as groups, and they are summarized on Table 1. AMS results from the 3 experiments are present in Tables 2, 3, and 4, respectively. All results were normalized to an independent set of OXI samples prepared using fresh perchlorate. 


\section{DISCUSSION}

From the first experiment (Table 2), we noticed that all of the $\Delta^{14} \mathrm{C}$ data from the OX-I "unknown" samples were lower than those of the normalizing standards prepared with fresh perchlorate $\left(\Delta^{14} \mathrm{C}=33.2 \pm 2.2 \%\right)$. The difference could not be explained. It was clearly not a fractionation effect since the Fraction Modern and $\Delta^{14} \mathrm{C}$ values in Table 2 have already been corrected for any graphitization or machine-induced isotopic fractionation (Pearson et al. 1998), using the on-line $\delta^{13} \mathrm{C}$ values. The differences were too large to be accounted for by memory from the 6 samples (all close to Modern) run previously in each reactor.

In the second and third experiment, there were no significant differences between the AMS ${ }^{14} \mathrm{C}$ results for OX-I samples prepared using different water removal treatments and the normalizing standards prepared with fresh $\mathrm{Mg}\left(\mathrm{ClO}_{4}\right)_{2}$ (Tables 3 and 4; Figure 3). At the level of precision of these tests, 3.8 and 3.3\%o, respectively, twice or 8 times previously used $\mathrm{Mg}\left(\mathrm{ClO}_{4}\right)_{2}$ appears to have no effect on $\Delta^{14} \mathrm{C}$. However, a larger spread in the results can be noticed when $\operatorname{Mg}\left(\mathrm{ClO}_{4}\right)_{2}$ was completely wet.

\section{OX-I}

First experiment 9 Second experiment 9 Third experimen

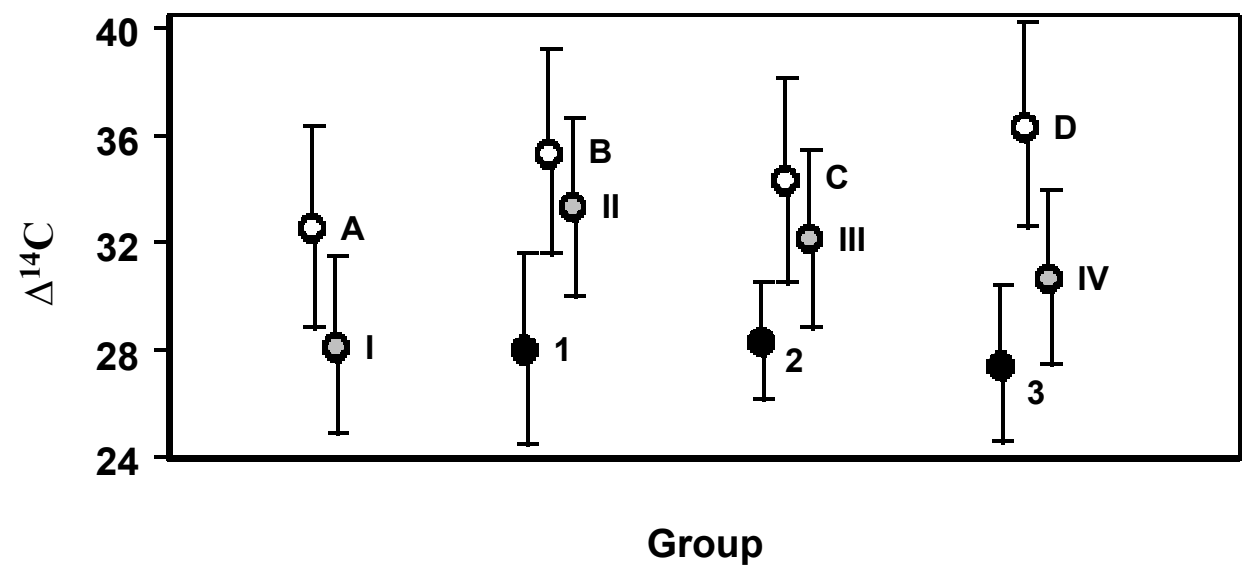

Figure $3 \Delta^{14} \mathrm{C}$ average and uncertainties of OX-I samples from the 3 experiments. Errors plotted represent the $1 \sigma$ scatter in the results from each group, or the statistical precision, whichever is greater. Groups of samples are shifted to better show the error bars.

In Table 3, we also compare AMS $\delta^{13} \mathrm{C}$ measurements with $\delta^{13} \mathrm{C}$ obtained on an Elemental Analyzer (EA) coupled with an IRMS from graphite produced in the second experiment. The EA $\delta^{13} \mathrm{C}$ results from aliquots of the graphite produced showed that there was no isotopic fractionation during graphitization (Table 3). However, machine-induced isotopic fractionation effects are clear on this second experiment.

For the background samples (USGS coals), the experiments seem more conclusive. We believe that the $\mathrm{CO}_{2}$ samples have been contaminated by modern $\mathrm{CO}_{2}$ trapped in water in the perchlorate (or in the perclorate itself) since the 4 different $\mathrm{CO}_{2}$ samples all show backgrounds improving as $\mathrm{Mg}\left(\mathrm{ClO}_{4}\right)_{2}$ wetness decreases and/or longer pumping time was applied (Figure 4). Note that none of these USGS coal samples are as good as the $54.3 \pm 0.6 \mathrm{ka}$ (background processed graphite) obtained with fresh perchlorate in the first experiment, for reasons which are unexplained. 


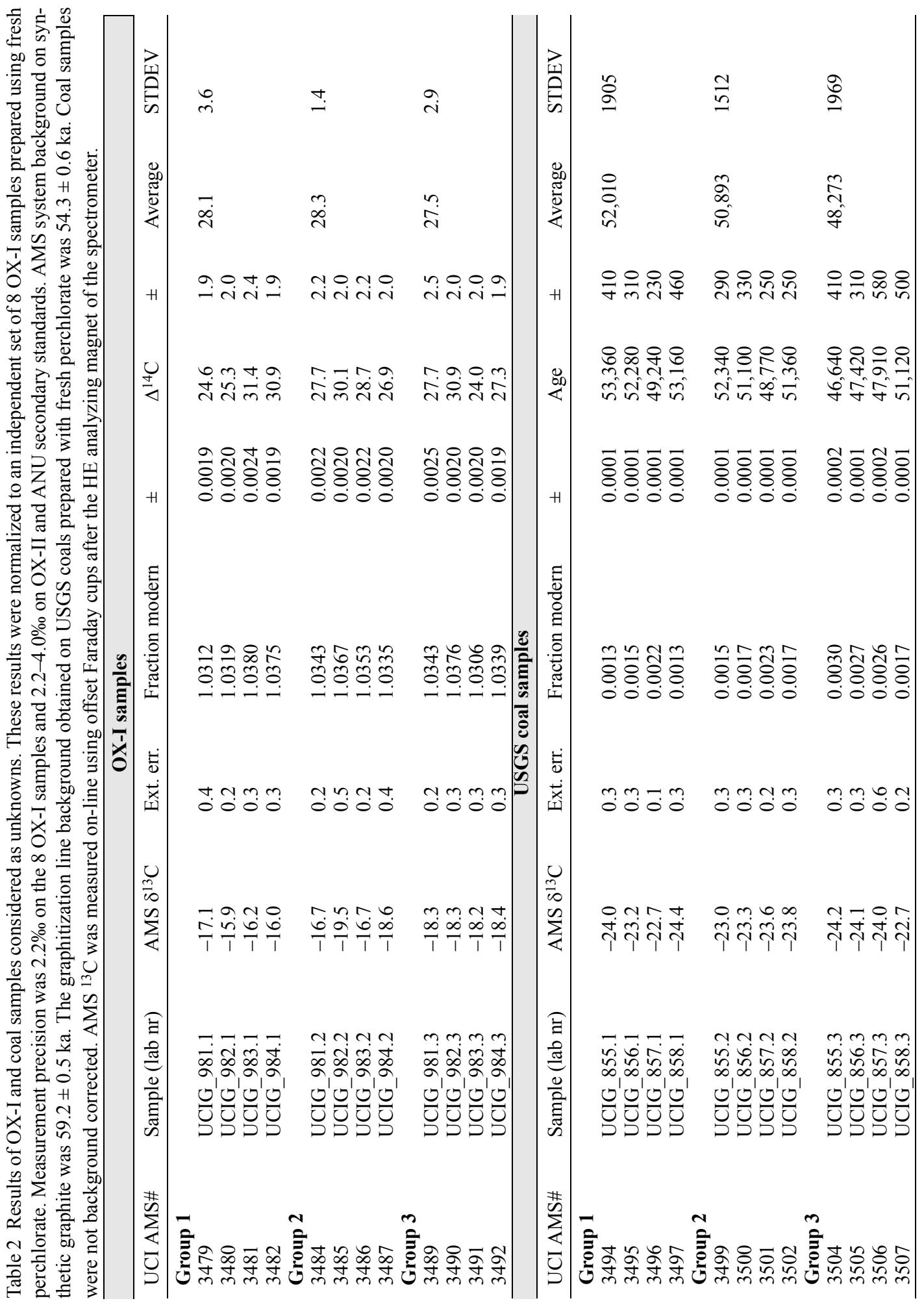




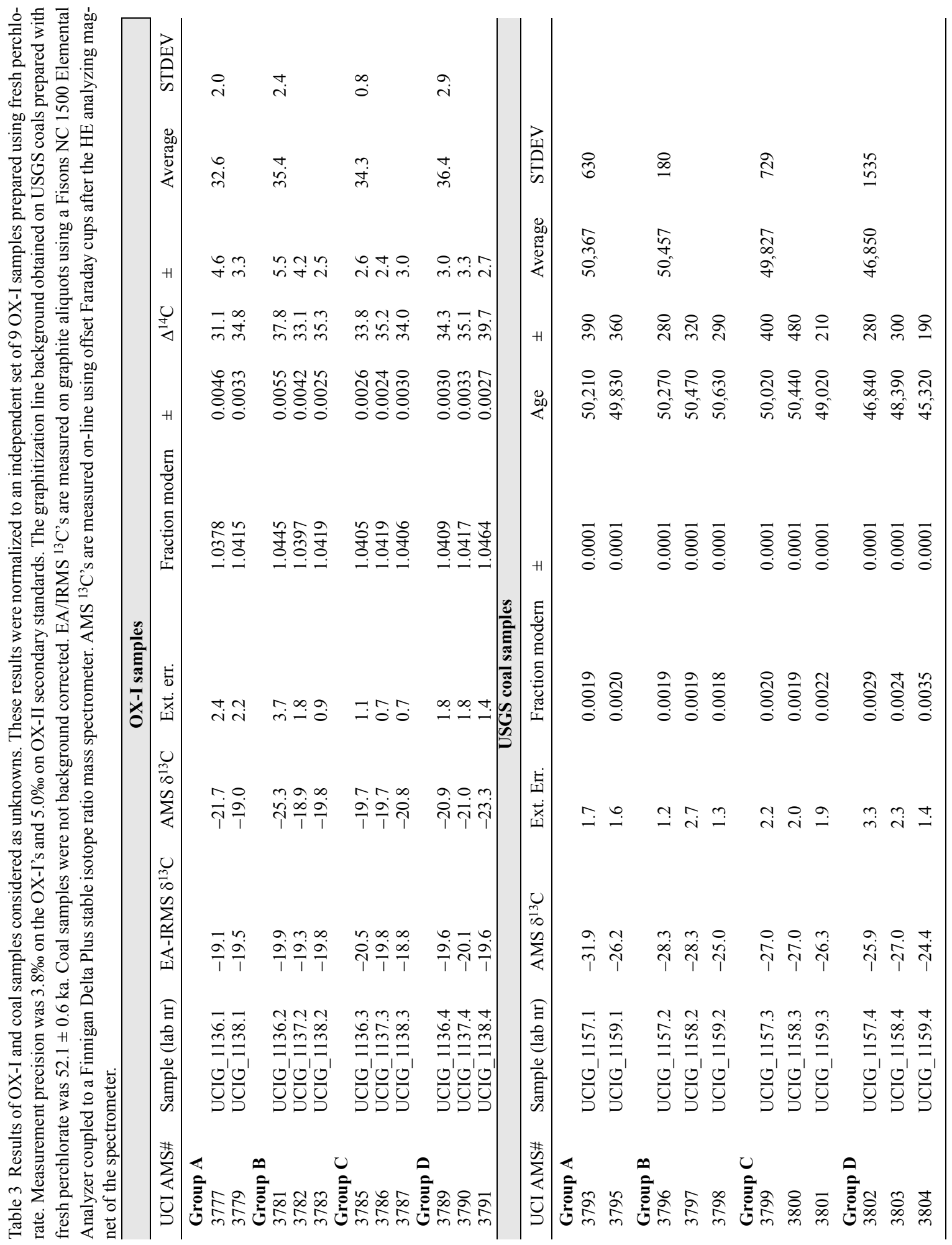


Table 4 Results of OX-I samples considered as unknowns. These results were normalized to an independent set of 7 OX-I samples prepared using fresh perchlorate. Measurement precision was 3.3\% on the OX-I samples and ANU secondary standards. The graphitization line background obtained on USGS coals prepared with fresh perchlorate was $49.8 \pm 1.4 \mathrm{ka}$. Coal samples were not background corrected.

\begin{tabular}{llllllllll}
\hline \multicolumn{1}{c}{ OX-I samples } \\
\hline UCI & $\begin{array}{l}\text { AMS } \\
\text { AMS\# }\end{array}$ & $\begin{array}{l}\text { Ext. } \\
\text { Sample (lab nr) }\end{array}$ & $\begin{array}{l}\text { Fraction } \\
\text { modern }\end{array}$ & $\begin{array}{l}\text { err. } \\
\text { modern }\end{array}$ & & $\Delta^{14} \mathrm{C}$ & \pm & Average & STDEV \\
\hline $\begin{array}{l}\text { Group 1 } \\
4329\end{array}$ & UCIG_1483.1 & -22.7 & 0.4 & 1.0338 & 0.0024 & 27.2 & 2.4 & 28.2 & 2.5 \\
4330 & UCIG_1484.1 & -20.3 & 0.3 & 1.0329 & 0.0024 & 26.3 & 2.4 & & \\
4331 & UCIG_1485.1 & -17.9 & 0.4 & 1.0376 & 0.0024 & 31.0 & 2.4 & & \\
Group 2 & & & & & & & & \\
4332 & UCIG_1483.2 & -18.3 & 0.4 & 1.0438 & 0.0024 & 37.1 & 2.4 & 33.4 & 3.2 \\
4333 & UCIG_1484.2 & -15.2 & 0.2 & 1.0382 & 0.0024 & 31.6 & 2.4 & & \\
4334 & UCIG_1485.2 & -18.2 & 0.4 & 1.0381 & 0.0028 & 31.4 & 2.8 & & \\
Group 3 & & & & & & & & \\
4337 & UCIG_1483.3 & -17.9 & 0.3 & 1.0385 & 0.0024 & 31.9 & 2.4 & 32.2 & 0.3 \\
4338 & UCIG_1484.3 & -17.6 & 0.3 & 1.0389 & 0.0028 & 32.3 & 2.8 & & \\
4339 & UCIG_1485.3 & -19.2 & 0.4 & 1.0391 & 0.0036 & 32.4 & 3.6 & & \\
Group 4 & & & & & & & & \\
4340 & UCIG_1483.4 & -20.1 & 0.4 & 1.0380 & 0.0024 & 31.4 & 2.4 & 30.7 & 1.1 \\
4341 & UCIG_1484.4 & -20.4 & 0.3 & 1.0379 & 0.0025 & 31.3 & 2.5 & & \\
4342 & UCIG_1485.4 & -18.6 & 0.4 & 1.0360 & 0.0034 & 29.4 & 3.4 & & \\
\hline
\end{tabular}

\section{USGS Coal}

- First experimento Second experiment

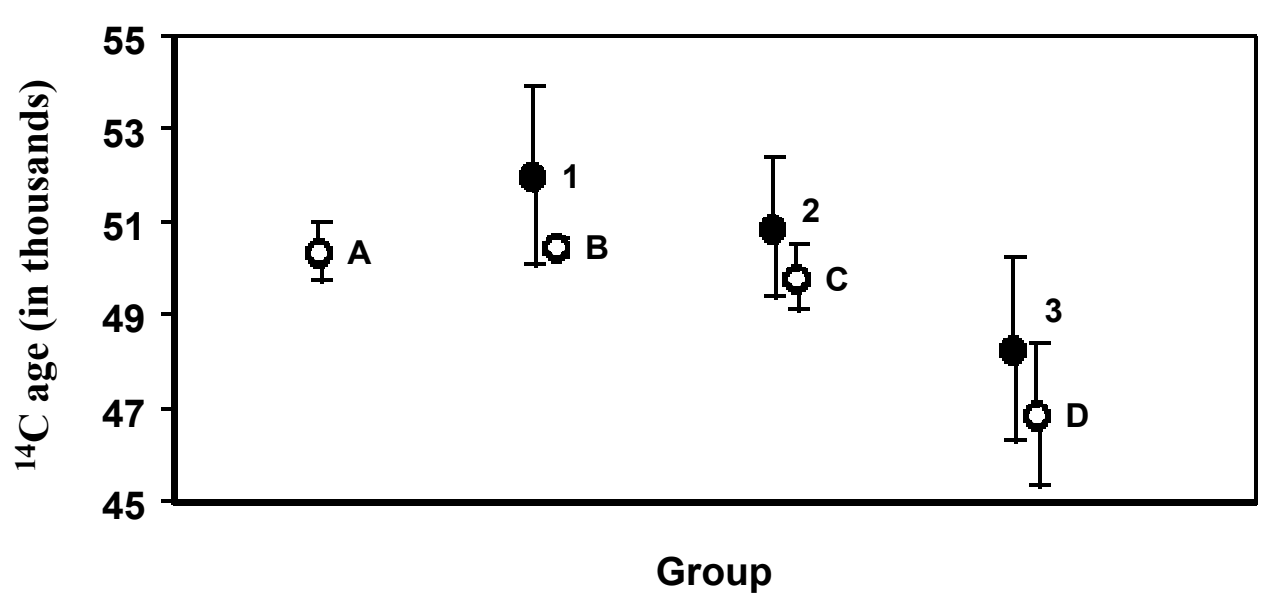

Figure $4{ }^{14} \mathrm{C}$ age averages for coal samples and respective errors from the 3 experiments. Errors plotted represent the $1 \sigma$ scatter in the results from each group. Groups of samples are shifted to better show the error bars. 
Overall, backgrounds were not as good at the time of the second experiment (e.g. compare the graphitization line backgrounds for the first and second tests cited in the table captions). Under these conditions, we saw no significant differences between results for coals graphitized using cryogenic mixtures (group A) or fresh mixtures (group B), and only minimal contamination for the twice previously used $\mathrm{Mg}\left(\mathrm{ClO}_{4}\right)_{2}$ (group C). On the other hand, a large background increase was observed for group $\mathrm{D}$, as for group 3 in the first experiment, where the $\mathrm{Mg}\left(\mathrm{ClO}_{4}\right)_{2}$ was wet.

These experiments had induced us to use the $\mathrm{Mg}\left(\mathrm{ClO}_{4}\right)_{2}$ during graphitization only 3 times before replacement. Overall precision has decreased over a period of several months from a range of $0.2-0.5 \%$ to $0.2-0.3 \%$. This improvement may not be due to changing the way we use the perchlorate, but it does demonstrate that the use of perchlorate is compatible with high precision. Backgrounds also improved and are frequently as old as $53 \mathrm{ka}$.

\section{CONCLUSION}

For ${ }^{14} \mathrm{C}$ measurements that do not require precision better than $0.3 \%$ or backgrounds better than 53 $\mathrm{ka}$, the use of $\mathrm{Mg}\left(\mathrm{ClO}_{4}\right)_{2}$ as an alternative water trap seems very convenient and reliable provided the $\mathrm{Mg}\left(\mathrm{ClO}_{4}\right)_{2}$ is replaced frequently. Variations in $\Delta^{14} \mathrm{C}$ are not significant when comparing dryfresh $\mathrm{Mg}\left(\mathrm{ClO}_{4}\right)_{2}$ with standard dry ice/ethanol cold fingers.

For measurements requiring better precision $(<0.2 \%)$ and/or backgrounds $(>53 \mathrm{ka})$, the $\mathrm{Mg}\left(\mathrm{ClO}_{4}\right)_{2}$ should be treated with some suspicion. In such cases, cryogenic mixtures or thermoelectric cooling may be preferable solutions for removing water during the graphitization reaction. As yet, we have no direct evidence to show exactly what mechanism causes the $\Delta^{14} \mathrm{C}$ shifts. However, it seems that the moisture content of the $\mathrm{Mg}\left(\mathrm{ClO}_{4}\right)_{2}$ is important and we suspect that trapping of $\mathrm{CO}_{2}$ in wet perchlorate plays a part.

\section{ACKNOWLEDGEMENTS}

We thank the W M Keck Foundation and the Dean of Physical Sciences and Vice Chancellor for Research, UCI, for financial support. Special thanks to Shuhui Zheng (pioneer in the use of $\mathrm{Mg}\left(\mathrm{ClO}_{4}\right)_{2}$ on hydrogen reduction graphite sample preparation) and Susan E Trumbore for valuable discussions. We owe special thanks to Christine Prior for her comments on the manuscript.

\section{REFERENCES}

Loyd DH, Vogel JS, Trumbore S. 1991. Lithium contamination in AMS measurement of ${ }^{14} \mathrm{C}$. Radiocarbon 33(3):297-301.

Pearson A, McNichol AP, Schneider RJ, von Reden KF, Zheng Y. 1998. Microscale AMS ${ }^{14} \mathrm{C}$ measurement at NOSAMS. Radiocarbon 40(1):61-75.
Southon JR, Santos GM, Druffel-Rodriguez K, Druffel E, Trumbore SE, Xu X, Griffin S, Ali S, Mazon M. The Keck Carbon Cycle AMS Laboratory, University of California, Irvine: initial operation and a background surprise. Radiocarbon, these proceedings. 